\title{
Gut microbiota-derived metabolites in obesity: a systematic review
}

\author{
Hanieh-Sadat EJTAHED ${ }^{1,2}$, Pooneh ANGOORANI ${ }^{1}$, Ahmad-Reza SOROUSH ${ }^{1}$, Shirin HASANI-RANJBAR ${ }^{1^{*}}$, \\ Seyed-Davar SIADAT ${ }^{2,3^{*}}$ and Bagher LARIJANI ${ }^{2}$ \\ ${ }^{1}$ Obesity and Eating Habits Research Center, Endocrinology and Metabolism Clinical Sciences Institute, Tehran University of Medical \\ Sciences, 5th Floor, Shariati Hospital, North Kargar Ave, 1411413137, Tehran, Iran \\ ${ }^{2}$ Endocrinology and Metabolism Research Center, Endocrinology and Metabolism Clinical Sciences Institute, Tehran University of \\ Medical Sciences, Tehran, Iran \\ ${ }^{3}$ Department of Mycobacteriology and Pulmonary Research, Microbiology Research Center, Pasteur Institute of Iran, Tehran, Iran
}

Received September 5, 2019; Accepted January 21, 2020; Published online in J-STAGE February 13, 2020

\begin{abstract}
Recent evidence suggests that gut microbiota-derived metabolites affect many biological processes of the host, including appetite control and weight management. Dysbiosis of the gut microbiome in obesity influences the metabolism and excretion of gut microbiota byproducts and consequently affects the physiology of the host. Since identification of the gut microbiota-host co-metabolites is essential for clarifying the interactions between the intestinal flora and the host, we conducted this systematic review to summarize all human studies that characterized the gut microbiota-related metabolites in overweight and obese individuals. A comprehensive search of the PubMed, Web of Science, and Scopus databases yielded 2,137 articles documented up to July 2018. After screening abstracts and full texts, 12 articles that used different biosamples and methodologies of metabolic profiling and fecal microbiota analysis were included. Amino acids and byproducts of amino acids, lipids and lipid-like metabolites, bile acids derivatives, and other metabolites derived from degradation of carnitine, choline, polyphenols, and purines are among the gut microbiota-derived metabolites which showed alterations in obesity. These metabolites play an important role in metabolic complications of obesity, including insulin resistance, hyperglycemia, and dyslipidemia. The results of this study could be useful in development of therapeutic strategies with the aim of modulating gut microbiota and consequently the metabolic profile in obesity.
\end{abstract}

Key words: obesity, gut microbiota, dysbiosis, metabolites, metabolic profile

\section{INTRODUCTION}

Obesity is a global epidemic disorder with a multifaceted etiology, including genetics and environmental factors [1]. The gut microbiota, the microbial community inhabiting the intestine, has been recently implicated as an important environmental factor in obesity and its related metabolic disorders [2-4]. The most abundant phyla of the human gut microbiota are Firmicutes and Bacteroidetes, the ratio of which is strongly associated with obesity [2]. It has been shown that the Bacteroidetes to Firmicutes ratio decreases in obesity but increases after weight loss following gastric bypass or calorie restriction [5]. However, some studies have reported inconsistent findings, and these differences should be investigated in lower taxonomic ranks [6, 7]. The gut microbiota is considered to be an endocrine organ because of its comprehensive metabolic ability and its extensive genes that influence the host [8]. Recent studies indicate that the obesity-related intestinal microbiota leads to alterations in some circulating metabolites and are associated with fasting levels of some metabolites, such as amino acids, fatty acids, lipids, and glucose $[9,10]$. The gut microbiota releases metabolites which can be passed through the intestinal barrier and eventually biotransformed by the host [11]. Metabolomics, the systematic study of low-molecular-weight molecules produced in biochemical pathways, is a strong method for recognition of the crosstalk between the gut microbiota and host metabolism [12]. Gut microbial species are the origin of key features of the serum metabolite profile associated with metabolic disorders, including obesity, insulin resistance, and cardiovascular diseases [9, 13]. The process used in metabolomics surveys is classified into five major phases: sample collection, sample preparation, data acquisition, data analysis, and biological interpretation of the

\footnotetext{
*Corresponding authors. Shirin Hasani-Ranjbar (E-mail: sh_hasani@tums.ac.ir); Seyed-Davar Siadat (E-mail: d.siadat@gmail.com) *Equally contributed as Corresponding authors. 
findings [14]. There are many targeted and untargeted metabolites profiling techniques capable of quantifying polar metabolites and molecular lipids present in biological samples, such as blood, urine and feces [15]. The most prevalent analytical techniques applied for the determination of the metabolic profile of a biological sample are liquid chromatography-mass spectrometry (LC-MS), gas chromatography-mass spectrometry (GC-MS), and nuclear magnetic resonance (NMR) [16].

Specific metabolites are strongly associated with gut microbial community structure, and some of these correlations are specific to the overweight or obesity state $[17,18]$. Therefore, we performed this systematic review to summarize all human studies that characterized the gut microbiota-related metabolites in overweight and obese individuals or focused on correlations between metabolites and gut microbiota in obesity.

\section{METHODS}

\section{Search strategy and study selection}

PubMed, Web of Science, and Scopus databases were searched for all human studies focused on the gut bacteriarelated metabolites in obesity. The search was restricted to English language studies with no restriction regarding publication date up to July 2018. The search terms included the following: Metabolom*, metabonom*, metabolite*, "metabolic profiling", "metabolic profile" AND "gut microbiota", "intestinal microbiota", "faecal microbiota", "gut microbiome", "intestinal microbiome", "faecal microbiome", "gut microbial profile", "faecal microbial profile", "gut flora" AND obesity, overweight, obese, adiposity.

Two researchers independently screened titles, abstracts, and then full-text articles to lessen selection bias. Disagreements between the two researchers were resolved by discussing until reaching consensus. Moreover, other relevant references in the selected articles were also reviewed. Targeted and untargeted metabolomics approaches were both included in the selection strategy. Low-molecular-weight $(<1,000 \mathrm{Da})$ metabolites related to gut microbiota which were significantly up- or downregulated in overweight and obese individuals compared with lean, healthy control subjects were the primary outcomes of interest of this systematic review. Some literature, including in vitro studies, animal studies, reviews, and studies conducted on nonobese hosts, were excluded from the systematic review. The present study was conducted according to the Preferred Reporting Items for Systematic Reviews and Meta-Analyses (PRISMA) guidelines.

\section{Data extraction}

Relevant data were extracted from the included studies by two researchers separately. Disagreements between the two investigators were resolved by discussion and consensus. The following information was extracted from the studies: authors; publication year; country of origin; study design; characteristics of the participants, including gender, age, ethnicity, and body mass index (BMI) range; fecal microbiota analysis method, platforms used for metabolites profiling; and the metabolites found to correlate with gut microbiota.

\section{RESULTS}

The search yielded 2,137 articles (PubMed, 738; Scopus, 692;
Web of science, 697; hand searching, 10), of which 2,125 were excluded because they were duplicates, irrelevant or animal studies, or reviews or they were missing outcome data (Fig. 1). Ultimately, 12 human studies successfully met the search criteria and were included in this systematic review. All studies were published between 2010 and 2018 (Table 1).

Most of the included studies compared metabolites in overweight or obese individuals with normal weight controls in different populations, including Chinese [9], Finnish [19-22], Swiss [23], American [24], Italian [25], Canadian [26], Mexican [27], and Arabian [28] populations. The age range varied from school-age children $[23,27]$ to young and middle age adults $[9$, 19-21, 24-26, 28, 29]. One study investigated obese women in early pregnancy [22]. The biological samples used in these studies consisted of serum and plasma samples (in 7 studies), fecal samples (in 3 studies), and urine samples (in 2 studies). The analytical platforms applied for targeted metabolic profiling consisted of ultra-high-performance liquid chromatography (UHPLC) coupled to triple quadrupole mass spectrometry (UPLC-QqQMS) [9, 19], gas-liquid chromatography [21, 29], high-pressure liquid chromatography (HPLC) [21, 23], nuclear magnetic resonance (NMR) spectroscopy [20], liquid chromatography with on-line tandem mass spectrometry (LC-MS/ MS) [20], gas chromatography-mass spectrometry (GC-MS) [21, $26,27]$, and a pulsed electrochemical detector [21]. The platforms for untargeted metabolic detection included gas chromatography coupled to time-of-flight mass spectrometry (GC_GC-TOFMS) [19], ultra-performance liquid chromatography coupled to quadrupole-TOFMS (UPLC-QTOFMS) [19], HPLC-MS [9], high-throughput proton NMR metabolomics [22], LC-MS [24], high-resolution proton NMR (1H NMR) spectroscopy [25], and NMR-based metabolic profiling [28]. The most used method for fecal microbiota analysis was $16 \mathrm{~S}$ ribosomal RNA amplicon sequencing [20, 22, 24, 27], and the other techniques included shotgun sequencing $[9,24]$, quantitative real-time PCR [21, 23, 29], denaturing gradient gel electrophoresis (DGGE) [19], phylogenetic microarray [29], temperature gradient gel electrophoresis (TGGE) [23], and multi-tag pyro-sequencing [26].

\section{DISCUSSION}

\section{Metabolites related to gut microbiota in obesity}

In this systematic review, we categorized several metabolites related to gut microbiota in obesity to simplify evaluation of potential mechanisms.

\section{Amino acids and metabolites produced from bacterial degradation of amino acids}

Gut microbiota manipulate several amino acids (AAs) from dietary or endogenous proteins. These amino acids have a role in the synthesis of metabolic end products produced by the gut microbiota. Therefore, alteration of the gut bacterial composition in obese subjects can play an important role in susceptibility to metabolic disorders by affecting amino acid bioavailability to the host.

Branched-chain and aromatic amino acids

Some kinds of amino acids, including branched-chain amino acids (BCAAs) — valine, leucine, and isoleucine - and aromatic amino acids (AAAs) - phenylalanine, tyrosine, and 


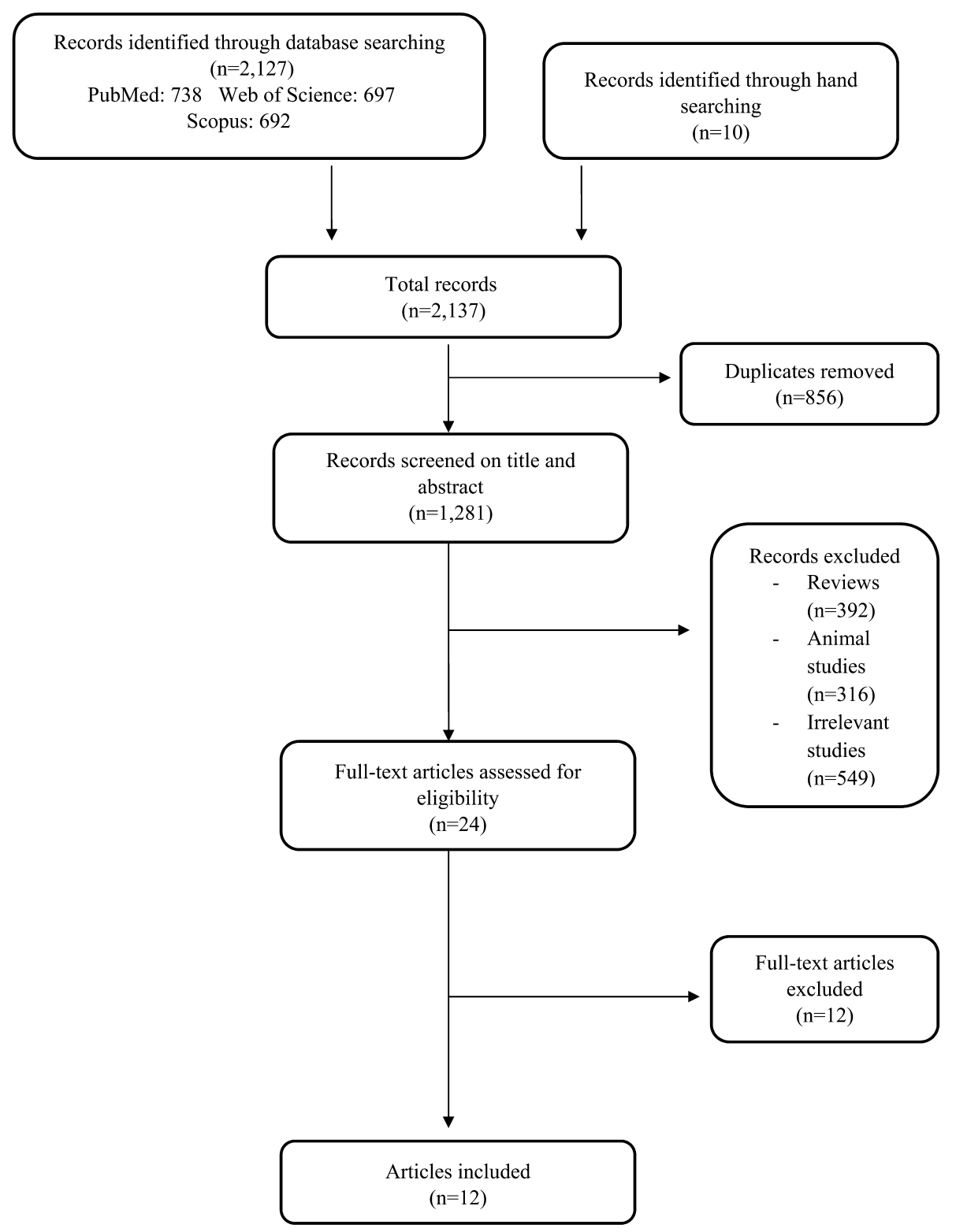

Fig. 1. Flow diagram of the systematic literature search.

tryptophan-have been reported as a risk factor for metabolic disorders, including obesity, insulin resistance, diabetes, and fatty liver [30-32]. With respect to obesity, Liu et al. [9] found that the serum levels of AAAs, glutamate, and BCAAs increased in obese subjects. They showed that the gut microbiota of obese individuals may have a higher capacity for production of these amino acids in comparison with lean controls [9].

The concentrations of aromatic amino acid-derived microbial metabolites, including benzoic acid (BA), phenylacetic acid (PAA), phenylpropionic acid (PPA), p-hydroxybenzoic acid (p-HBA), p-hydroxyphenylacetic acid (p-HPAA), 3,4-dihydroxyphenylacetic acid (3,4-DHPAA), indoleacetic acid (IAA), indole propionic acid (IPA), and 5-hydroxyindoleacetic acid (5-HIAA), which are produced through deamination, transamination, decarboxylation, and dehydrogenation reactions, are altered in metabolic disorders [33]. In a recent animal study, Konopelski et al. [34] found that a tryptophan-rich diet reduced weight gain in rats compared with a control group via an increase in production of gut bacteria-derived indole propionic acid from tryptophan. This evidence suggested the potential role of gut microbiota-produced metabolites in weight management [34]. In response to feeding a high-fat diet to rat models, metabolism and elimination of p-HPAA, a metabolite produced from tyrosine by gut microbiota, altered in such a way that the p-HPAA concentration decreased in urine while it increased in serum and feces. p-HPAA can be further metabolized to p-cresol through decarboxylation by Clostridium difficile. These alterations suggest the underlying mechanisms of accumulation of p-cresol and overgrowth of $C$. difficile in obesity [35]. Furthermore, an animal experiment reported that 3,4-DHPAA, which could protect against pancreatic $\beta$-cell dysfunction, increased in obese rats as a potential protection in response to obesity [36]. Moreover, the urinary concentration of the indolic compound 5-HIAA, a clinical indicator of gastrointestinal carcinoid tumors, was elevated in 


\begin{tabular}{|c|c|c|c|c|c|c|c|c|}
\hline & 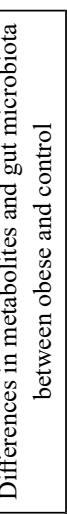 & 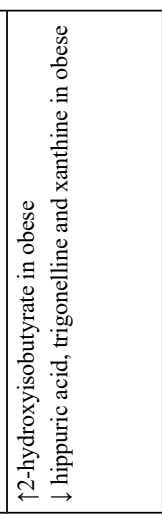 & 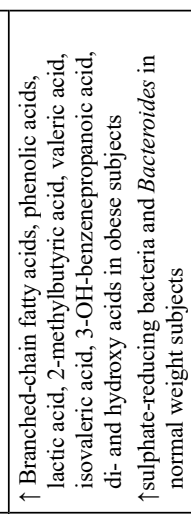 & 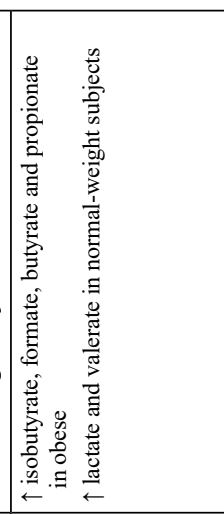 & 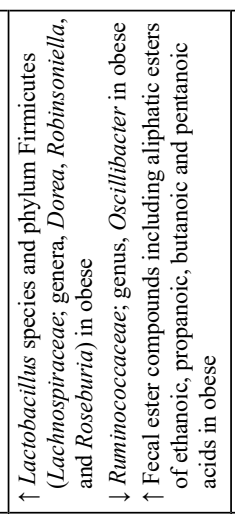 & & & 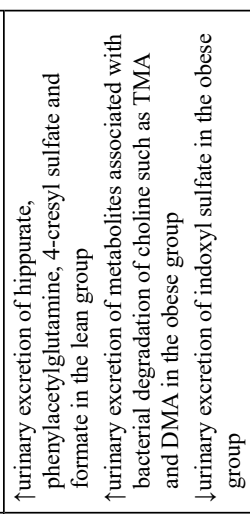 \\
\hline & 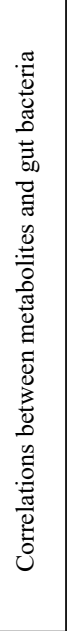 & 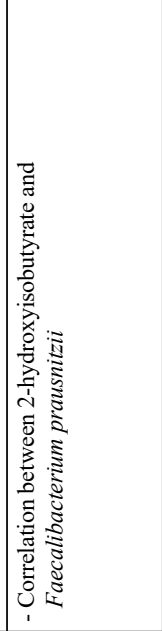 & & 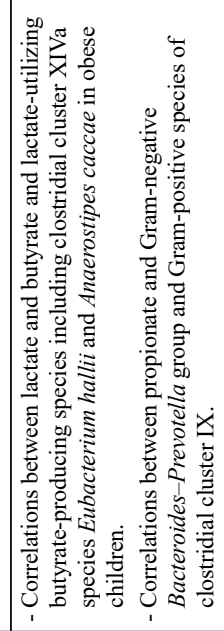 & & 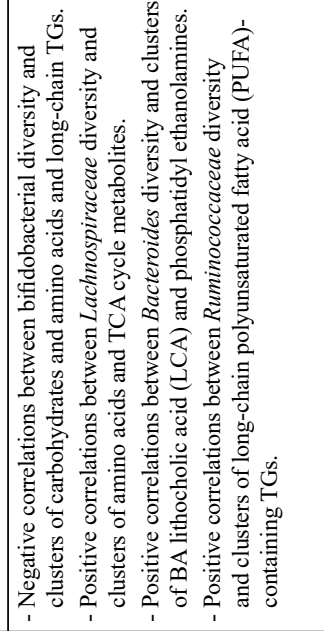 & 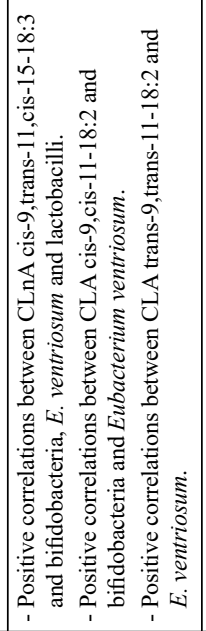 & \\
\hline & 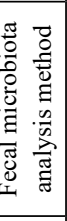 & & 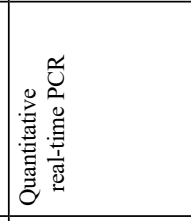 & 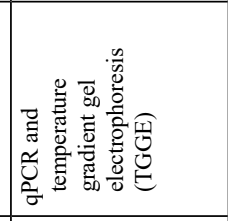 & 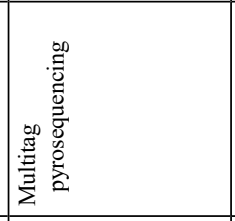 & 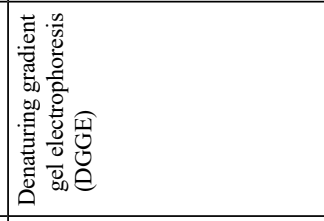 & 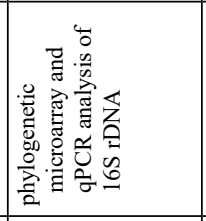 & \\
\hline & $\begin{array}{l}\text { 志 } \\
\text { 壳 } \\
\frac{0}{2}\end{array}$ & 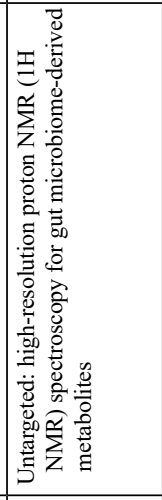 & 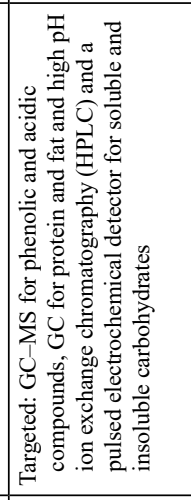 & 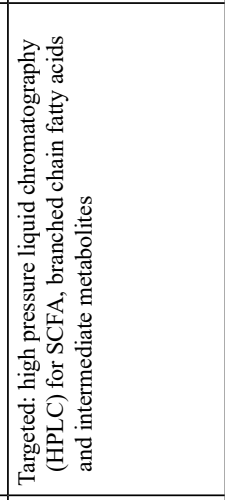 & 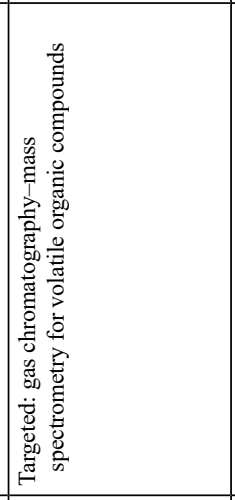 & 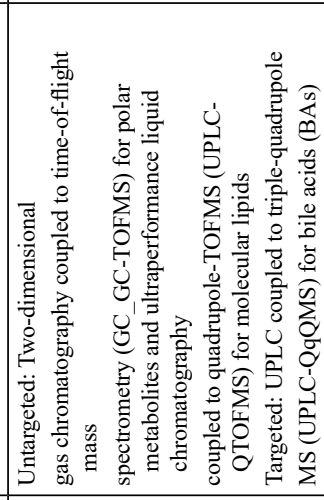 & 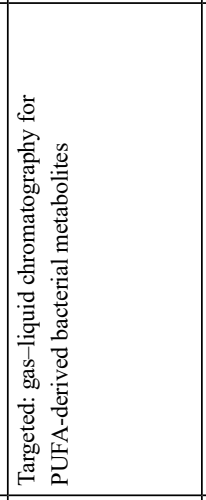 & 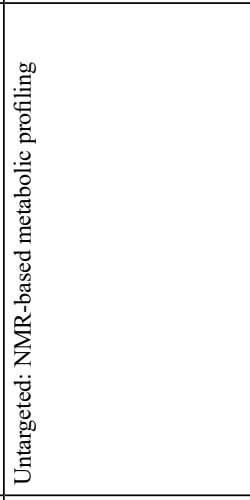 \\
\hline & 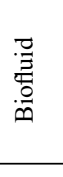 & 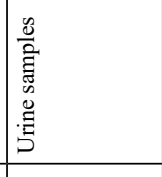 & 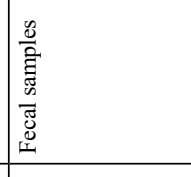 & 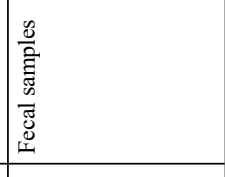 & 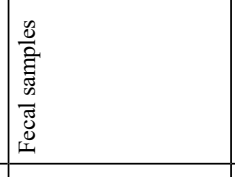 & $\begin{array}{l}\frac{\tilde{a}}{\tilde{g}} \\
\frac{\tilde{g}}{2}\end{array}$ & \begin{tabular}{|l|} 
\\
咅 \\
n. \\
\end{tabular} & 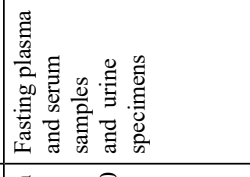 \\
\hline & 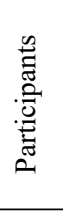 & 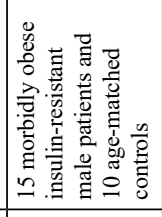 & 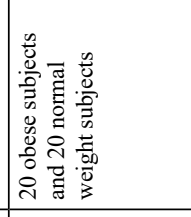 & 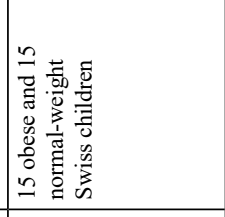 & 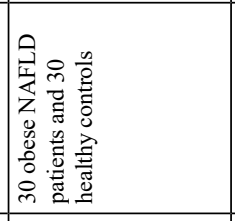 & 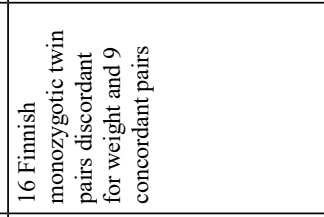 & 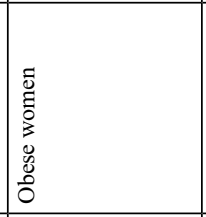 & 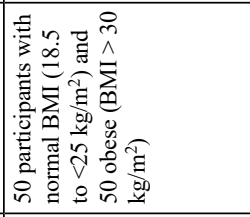 \\
\hline & 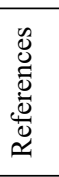 & 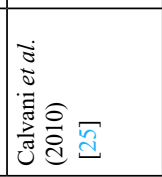 & 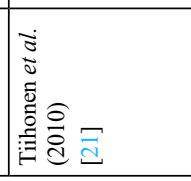 & 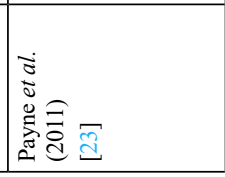 & 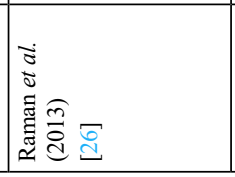 & 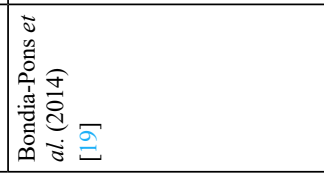 & 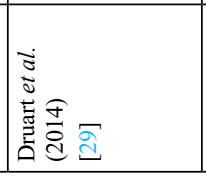 & 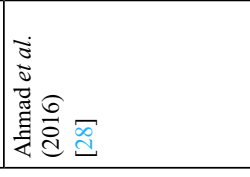 \\
\hline
\end{tabular}




\begin{tabular}{|c|c|c|c|c|c|}
\hline 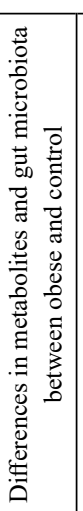 & 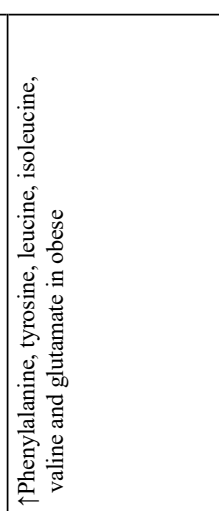 & 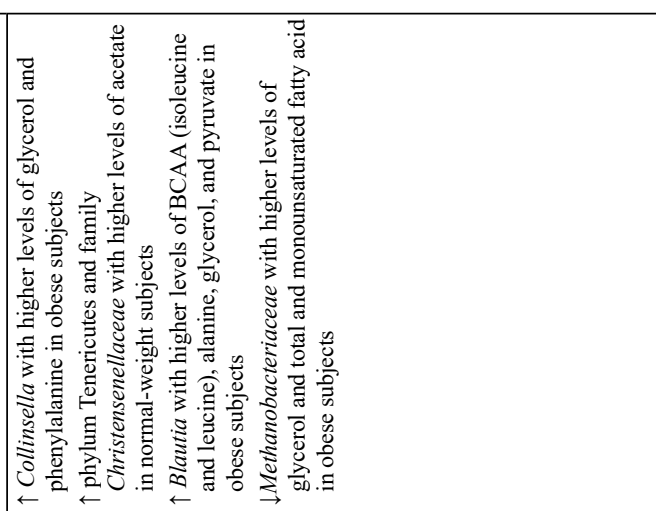 & 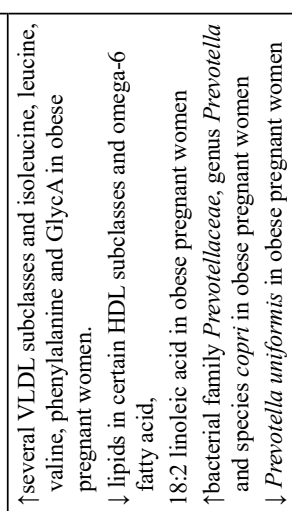 & 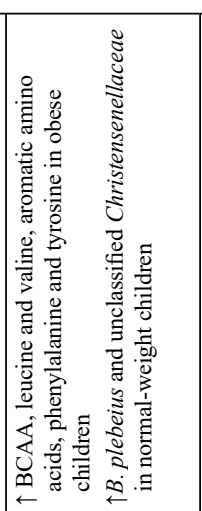 & \\
\hline 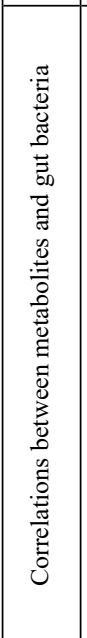 & 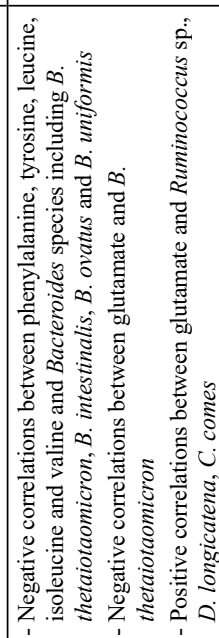 & 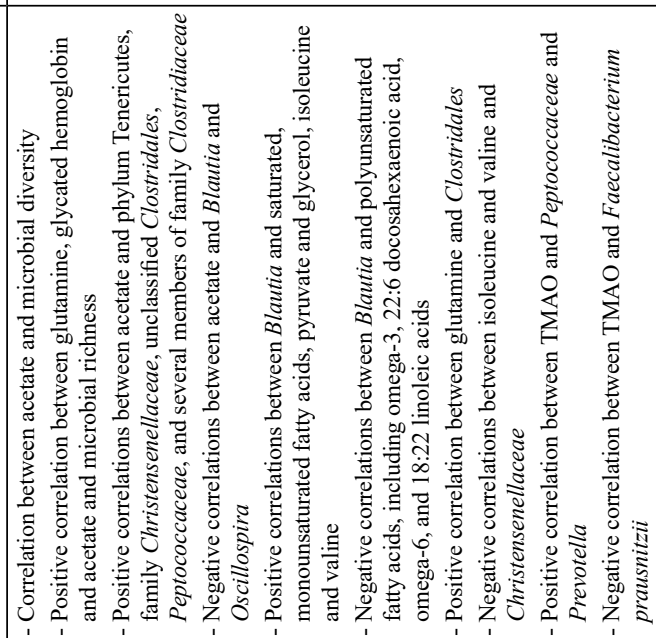 & 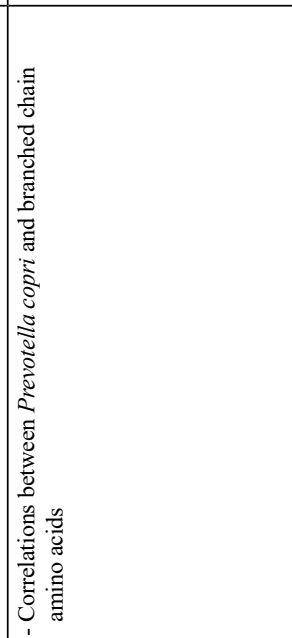 & 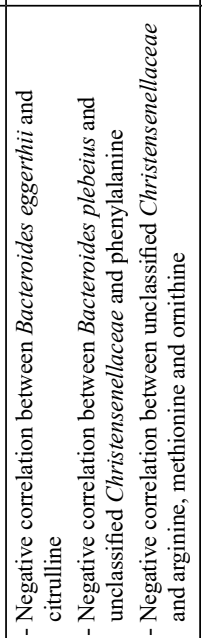 & 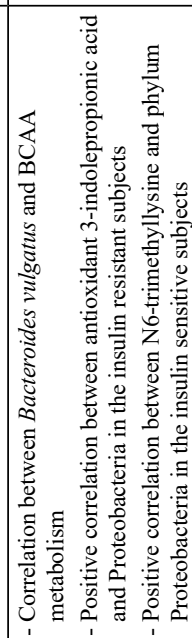 \\
\hline 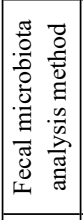 & 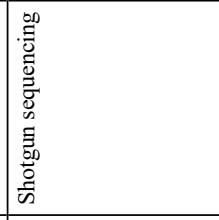 & 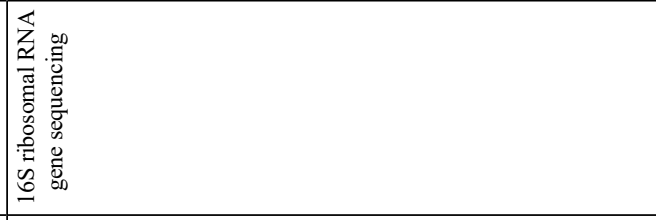 & 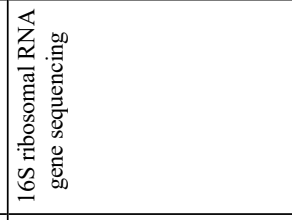 & 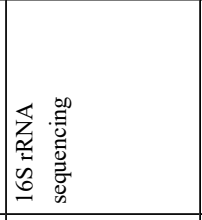 & 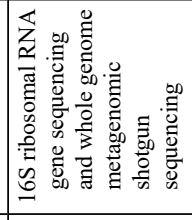 \\
\hline 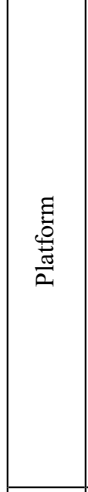 & 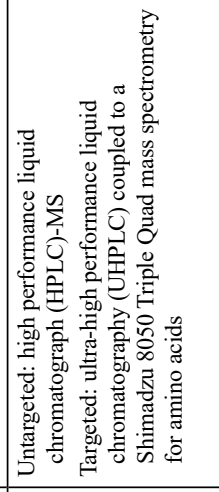 & 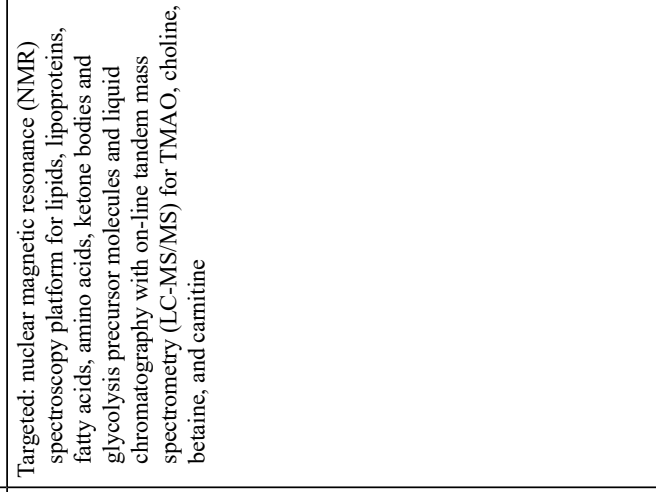 & 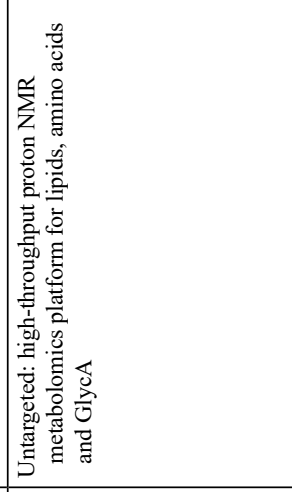 & 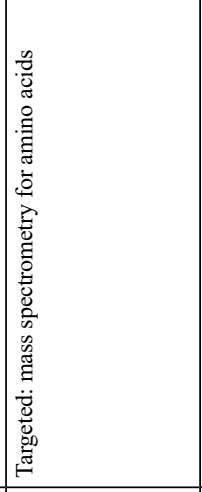 & 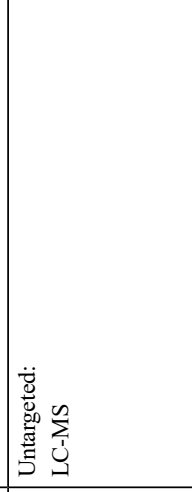 \\
\hline 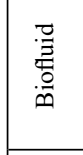 & 言 & 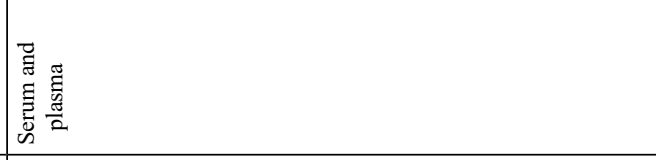 & 咅 & 言 & 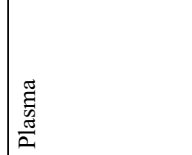 \\
\hline 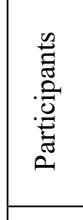 & 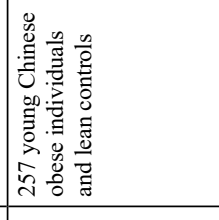 & 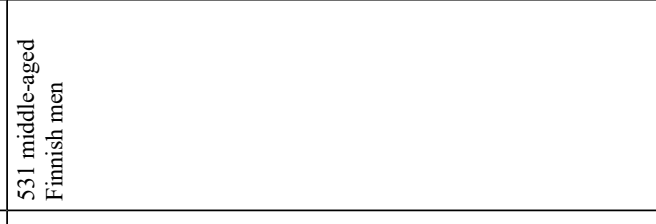 & 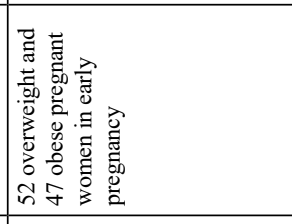 & 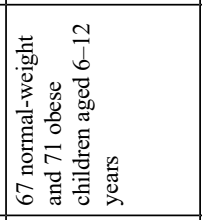 & 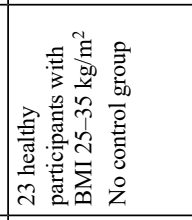 \\
\hline 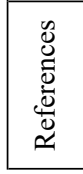 & 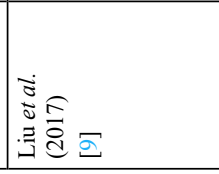 & 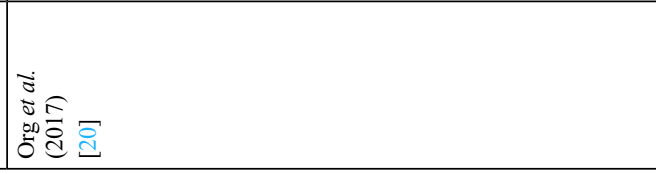 & 产 & 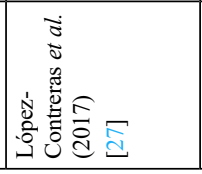 & 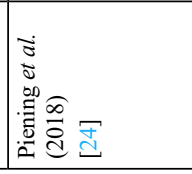 \\
\hline
\end{tabular}


obesity by the monoamine oxidase activity of Escherichia coli [37].

Org et al. [20] and Piening et al. [24] also showed higher serum and plasma levels of BCAAs and phenylalanine in obese subjects and individuals with high insulin resistance values. BondiaPons et al. [19] revealed that plasma BCAAs were increased in heavier twins compared with leaner co-twins in the fasting state. These amino acids were negatively correlated with Bacteroides species, including $B$. thetaiotaomicron, B. intestinalis, B. ovatus, and B. uniformis [9], and Christensenellaceae [20]. It has been demonstrated that $B$. thetaiotaomicron and $B$. ovatus can ferment AAAs to produce phenylacetic acid [38]. Piening et al. [24] showed a correlation between BCAAs and B. vulgatus, which has been shown to be a mediator between BCAA metabolism and insulin resistance [13]. Altogether, the changes in gut microbiota, especially the depletion of species from the Bacteroides genus in obese individuals, may be related to the higher concentration of AAAs and BCAAs in circulation [19]. These amino acids are known risk factors for insulin resistance, hyperglycemia, hyperlipidemia, elevated circulating inflammatory factors, diabetes, and cardiovascular diseases [9, 39, 40]. They may also directly promote insulin resistance, possibly by disconnecting insulin signaling in skeletal muscle [41]. Recent studies have indicated that ribosomal protein S6 kinase 1 (S6K1) is sensitive to both insulin and some nutrients, including amino acids, and that amino acids also negatively affect insulin signaling through phosphorylation of insulin receptor substrate 1 (IRS1) [42].

In a study on overweight and obese women in early pregnancy, Houttu et al. [22] showed that the serum concentrations of BCAAs and phenylalanine were significantly higher in the obese pregnant women compared with the overweight ones. They also observed a higher abundance of Prevotella copri and a lower abundance of Prevotella uniformis in obese compared with overweight pregnant women [22]. However, the findings of this study could have been influenced by the fact that the gut microbiota composition may change during pregnancy [43]. Prevotella copri, which belongs to the phylum Bacteroidetes, is associated with biosynthesis of BCAAs and subsequent development of insulin resistance [13]. Ottosson et al. [44] showed that higher abundances of all BCAAs and byproducts of BCAA metabolites in plasma, such as branched-chain keto acids (3-methyl-2-oxovalerate, a-ketoisovalerate, and a-ketoisocaproate) and short-chain acylcarnitines (propionylcarnitine and isovalerylcarnitine), were correlated with higher BMI. They revealed correlations between four gut microbiota genera (Blautia, Dorea, Ruminococcus, and SHA-98) and BCAAs and glutamate, which are BMI-predictive metabolites. Therefore, these metabolites could be underlying mechanisms connecting gut microbiota and obesity. Three of these genera, Blautia, Dorea, and Ruminococcus, are members of the Lachnospiraceae family, one of the most abundant families in the gut microbiota. Two bacterial genera, $S H A-98$ and a genus in the Rikenellaceae family, were correlated with a lower BMI [44]. Dorea and Ruminococcus have been found to be connected to metabolic syndrome and weight gain $[45,46]$.

Glutamate

The other important gut microbiota-derived AA in obesity is glutamate. Glutamate is a secondary product of the first step of BCAA catabolism. It is significantly related to obesity and gut bacterial genera, including Blautia, Dorea, Ruminococcus, and SHA-98 [44]. Glutamate has been shown to exhibit the most remarkable increase in obese individuals compared with lean controls $[9,20]$. The serum concentration of glutamate exhibited positive correlations with obesity features, such as BMI, waist to hip ratio (WHR), waist circumstance (WC), insulin resistance, and triacylglycerol [9]. Positive correlations were observed between glutamate and Ruminococcus spp., Dorea longicatena, Coprococcus comes [9], and Clostridiales [20]. A recent survey revealed that $B$. thetaiotaomicron colonization increases the levels of mRNAs encoding glutamate transporter and glutamate decarboxylase in epithelial cells, which may influence host glutamate levels [47]. Dorea longicatena expression is associated with obesity and increased levels of glutamate [44]. The level of B. thetaiotaomicron, a glutamate-fermenting species, decreases in the gut microbiota of obese subjects. Moreover, serum glutamate was shown to be inversely correlated with the abundance of $B$. thetaiotaomicron, which possesses genes encoding glutamate decarboxylase. Therefore, the depletion of $B$. thetaiotaomicron may contribute to the higher circulating concentration of glutamate in obesity [9].

It has been documented that glutamate, which is used as a common food additive, is able to induce obesity when administered to rodents [48]. Excessive glutamate consumption has been shown to be positively correlated with overweight in Chinese adults [49]. On the other hand, some studies indicated a protective effect of glutamine versus glutamate and demonstrated that glutamine supplementation altered the gut microbiota composition and improved glucose tolerance and obesity [32, 50]. Glutamine is essential for maintaining the overall nitrogen balance by providing mediators to the tricarboxylic acid cycle and for its ammonia carrying potential [51]. The utility of glutamine in metabolic impairments could be due to mechanisms such as higher release of glucagon-like peptide 1 (GLP-1), externalization of glucose transporter type 4 (GLUT-4), transcription of insulindependent enzymes, pancreatic beta-cell insulin secretion, and insulin sensitivity of adipose tissue [52]. Glutamate exhibited positive correlations with 16 obesity-enriched metagenomic linkage groups (MLGs) and negative correlations with 18 controlenriched MLGs that harbored genes encoding enzymes involved in glutamate metabolism $[9,53]$. In particular, obesity-enriched Ruminococcus spp., Dorea longicatena, and Coprococcus comes, which possessed genes encoding enzymes required to produce glutamate from glutamine, were positively correlated with circulating glutamate levels and negatively correlated with glutamine levels [9]. These observations suggest that the levels of glutamate and glutamine in circulation may reflect the changes in the abundance of these bacterial species.

Altogether, these data suggest that amino acid metabolism by gut microbial species may modulate the levels of circulating amino acids that are correlated with obesity and its metabolic complications.

Other amino acids and related metabolites

Negative correlation has been observed between some amino acids, including arginine, methionine, and ornithine, and unclassified Christensenellaceae, a gut microbial species associated with lower risk of obesity [27]. Other studies have reported higher levels of Christensenellaceae in subjects with normal weights $[54,55]$. It has also been shown that germ-free mice transplanted with fecal samples incubated with Christensenella minuta, a cultured member of the Christensenellaceae family, gained significantly less weight than 
mice treated with unamended stool [55]. However, the underlying mechanism of the effect of Christensenellaceae on BMI of the host is unclear.

Besides the mentioned AAs, two AA-related metabolites, 3-indolepropionic acid and N6-trimethyllysine, were also evaluated in a study by Piening et al. [24]. They revealed that in insulin-resistant subjects, the plasma level of 3-indolepropionic acid was positively associated with the abundance of Proteobacteria, a phylum that has been shown to increase in obese subjects [56]. N6-trimethyllysine was also positively associated with the Proteobacteria exclusively in insulinsensitive individuals [24]. 3-Indolepropionic acid is a microbial fermentation product from tryptophan which could be a potential drug target for the management of insulin resistance [57]. This metabolite has been shown to be associated with insulin resistance [13]. N6-trimethyllysine, a methylated derivative of lysine, is a precursor for L-carnitine biosynthesis, which improves glucose tolerance and increases total energy expenditure in obesity [58]. These findings show that there are microbial differences between insulin-resistant and insulin-sensitive subjects and that they are related to differences in the metabolism of the host.

The other AA-derived metabolite is indoxyl sulfate, a metabolite of dietary L-tryptophan, which is catalyzed by tryptophanase produced by gut microbiota [59]. Ahmad et al. [28] reported decreased excretion of indoxyl sulfate in obese subjects. An inverse relationship of indoxyl sulfate with BMI has also been shown in other animal and human studies [60, 61]. Furthermore, it has been shown that Bifidobacterium can metabolize indole to form indoxyl sulfate [62]. So, the lower abundance of Bifidobacterium in obese subjects can explain the low levels of indoxyl sulfate in overweight/obese individuals.

\section{Lipids and lipid-like molecules}

Alterations in gut microbiota have been shown to be associated with lipid and lipid-like metabolites which may affect lipid metabolism and obesity by increasing substrates for energy metabolism in the liver and peripheral tissues [63]. Increased levels of lipids and free fatty acids are known risk factors for metabolic syndrome, insulin resistance, and obesity, but different types of lipids have been shown to exert contradictory metabolic effects $[64,65]$.

Short-chain fatty acids

The important gut microbiota-derived lipids which might affect energy balance and weight changes in humans are shortchain fatty acids (SCFAs) [2]. SCFAs (acetate, propionate, and butyrate) resulting from the colonic fermentation of digestionresistant starch may provide an estimated additional $10 \%$ daily dietary energy to the host and can be used for de novo hepatic triglyceride and glucose synthesis [66]. Moreover, SCFAs could have a role in releasing satiety hormones [67]. They have been suggested to be signaling molecules for production of peptide YY (PYY) by enteroendocrine cells and thus decrease gut motility and further increase SCFA absorption and energy extraction from the gut lumen [68]. SCFAs, especially butyrate, significantly increase plasma levels of gastric inhibitory peptide (GIP), glucagon-like peptide 1 (GLP-1), PYY, insulin, and amylin, which would have a net effect on slowing digestion and nutrient intestinal transit, promoting satiety, and increasing plasma insulin. Acetate is reported to increase leptin released by fat cells; propionate increases G-protein-mediated secretion of PYY and GLP-1 in the gut and controls the rates of lipolysis and lipogenesis in fat cells [69]. However, there are inconsistent findings regarding the role of these compounds in obesity and its complications. Metabolic analyses of the feces of obese and normal-weight adults have identified increased levels of SCFAs in obese individuals [7]. Payne et al. [23] showed that fecal SCFAs, including isobutyrate, formate, butyrate, and propionate, increased in obese children but that lactate and valerate were elevated in normal-weight subjects. They found a correlation between lactate and butyrate with lactateutilizing and butyrate-producing species, including clostridial cluster XIVa species Eubacterium hallii and Anaerostipes caccae, in obese children. They also showed correlations between fecal propionate and the Gram-negative Bacteroides-Prevotella group and Gram-positive species of clostridial cluster IX [23]. These species may contribute to glucose and lipid metabolism through the produced metabolites, including propionate and acetate, that participate in gluconeogenesis and synthesis of cholesterol and de novo synthesis of lipids, respectively [70]. Prevotella uniformis has been found to decrease metabolic and immune dysfunction by affecting macrophage and dendritic cell function and intestinal dysbiosis in obese mice consuming a high-fat diet [71].

The major microbiota phyla affecting SCFA production in the gut are Firmicutes and Bacteroidetes [72]. Blautia is a common gut habitant belonging to the family Lachnospiraceae, which is one of the major taxonomic groups of the human gut microbiota that degrade complex polysaccharides to SCFAs. It has the ability to ferment a large variety of organic substrates, enabling flexible growth in the colon. Different bacterial species in the Blautia genus have been associated with obesity [73]. There is an association between Blautia and human genetic variants in a genomic region that has been associated with obesity and BMI [74]. Furthermore, SCFAs have been reported to be positively associated with Prevotella, Alistipes, and Barnesiella and negatively correlated with Bacteroides and Enterococcus. It is notable that Prevotellaceae has been shown to increase in obese individuals [75].

Triglycerides, cholesterol, and saturated and unsaturated fatty acids

Some microbial species have been found to alter the blood triglycerides and cholesterol fatty acids and thus can also influence host energy and lipid metabolism by regulating serum lipid levels. Org et al. [20] showed that Blautia was positively correlated with serum saturated fatty acids (SFAs) and monounsaturated fatty acids (MUFAs) but negatively correlated with acetate and polyunsaturated fatty acids (PUFAs), including omega-3, 22:6 docosahexaenoic acid, omega-6, and 18:22 linoleic acids. They also showed an increased abundance of Blautia in individuals with high BMI levels. The serum triglyceride (TG) level was associated with higher abundances of genus Methanobrevibacter from Archaea and Tenericutes, a phylum of bacteria. However, Peptococcaceae and Christensenellaceae were associated with lower TG levels [20].

Tiihonen et al. [21] showed increased fecal concentrations of BCFAs, including 2-methylbutyric acid and isovaleric acid, in obese subjects. BCFAs synthesized from proteins and amino acids are precursors of long-chain fatty acids and aldehydes. It should be noted that some gut bacteria, such as Bacteroides succinogenes, need both branched-chain volatile fatty acids (e.g., isobutyric acid) and straight-chain fatty acids (e.g., valeric acid) for growth. BCFAs can also be used as nitrogen donors for other 
important amino acids, such as glutamine and alanine, which both serve as an energy source for the gastrointestinal tract [76, 77].

Houttu et al. [22] showed that serum lipids in certain highdensity lipoprotein cholesterol (HDL-C) subclasses, omega-6 fatty acid, 18:2 linoleic acid, the ratio of PUFAs to total fatty acids, and the estimated degree of unsaturation of fatty acids were decreased but that several very-low-density lipoprotein cholesterol (VLDL-C) subclasses were increased in obese pregnant women.

Bondia-Pons et al. [19] found a negative correlation between Bifidobacterial diversity and plasma long-chain TGs and positive correlations between Ruminococcaceae diversity and clusters of PUFA-containing TGs, sphingomyelins, and other phospholipids. The postprandial changes of medium-chain fatty acids and monounsaturated fatty acids containing TGs were both negatively associated with liver fat and intra-abdominal fat. Postprandial changes of TGs with odd-chain fatty acids in plasma were negatively associated with the diversity of Lachnospiraceae, thus suggesting that this group may be involved in the metabolism of dietary lipids. Furthermore, the diversity of Bacteroides spp. was associated negatively with postprandial changes of unsaturated medium-chain TGs in plasma [19].

Conjugated linolenic acid (CLnA) and conjugated linoleic acid (CLA) are two important PUFA-derived metabolites with proven beneficial effects on weight loss. Druart et al. [29] showed positive correlations between the serum concentrations of both CLnA and CLA and Bifidobacterium, Eubacterium ventriosum, and Lactobacillus abundances. They also found negative correlations between these metabolites and the blood cholesterol profile, suggesting a potential beneficial effect of some PUFAderived bacterial metabolites [29]. The effects of CLA on body composition appear to be due in part to reduced fat deposition and increased lipolysis in adipocytes, possibly coupled with enhanced fatty acid oxidation in both muscle cells and adipocytes; however, CLnA modulates the body fat and TG metabolism differently from CLA by an unclear mechanism [78, 79]. These associations thus suggest a potential role of these bacterial species in the production of CLA and CLnA in vivo in humans. In fact, it has been demonstrated in vitro that Bifidobacterium can produce both CLA and CLnA but that Eubacterium ventriosum and Lactobacillus only produce CLA [80, 81].

\section{Bile acid derivatives}

Primary bile acids, including cholic and chenodeoxycholic acids, are formed from cholesterol in the liver, conjugated to either taurine or glycine, and then excreted into the gastrointestinal tract. They are deconjugated by several gram-positive bacterial species, such as lactobacilli, and after additional microbial modifications create over 50 different secondary bile acids in human feces [82]. Bile acids, which are hydroxylated steroids, contribute to the digestion of dietary lipids in the gut and have a signaling function [83]. Increased primary bile acid biosynthesis has been shown to be associated with obesity; however, higher levels of secondary bile acids are observed in normal-weight individuals [84]. Secondary bile acids affect energy expenditure and glucose homeostasis via their impacts on gluconeogenesis, insulin secretion, and insulin sensitivity [85]. The concentration and composition of bile acids in the gastrointestinal tract can influence carbohydrate and lipid metabolism, so they can alter the rate of weight loss [86]. Aleman et al. [87] showed significant positive associations between secondary bile acid metabolism and Christensenellaceae. They also reported a negative correlation between Christensenellaceae and weight loss [87].

It has been shown that bile acids are the key metabolic mediators between the gut microbiota and the host metabolism [88]. The gut microbiota has a profound effect on bile acid metabolism by promoting deconjugation, dehydrogenation, and dehydroxylation of primary bile acids in the distal small intestine and colon [41]. Bondia-Pons et al. [19] showed positive correlations between Bacteroides diversity and plasma clusters of the bile acid lithocholic acid (LCA) and phosphatidylethanolamines. Bile acids are predominantly conjugated to glycine in humans and to taurine in mice. They are critical regulators of hepatic lipid and glucose metabolism and influence signaling pathways via two receptors with pleiotropic functions, the nuclear farnesoid $\mathrm{X}$ receptor (FXR) and the G protein-coupled bile acid receptor TGR5 [41]. The gut microbiota modulates bile acid synthesis by changing the bile acid pool composition and by alleviating FXR inhibition in the small intestine.

\section{Metabolites derived from bacterial degradation of carnitine and choline}

Trimethylamine $\mathrm{N}$-oxide (TMAO) is generated through a two-step pathway that begins with the conversion of dietary nutrients such as phosphatidylcholine, choline, and carnitine into trimethylamine (TMA) by the gut microbiota. TMA then circulates to the liver, where it is oxidized into TMAO. It has been shown that the urinary excretion of metabolites associated with bacterial degradation of choline, such as TMA and dimethylamine (DMA), increased in an obese group [28]. Org et al. [20] showed that serum TMAO was positively correlated with Peptococcaceae and Prevotella but negatively correlated with Faecalibacterium prausnitzii. Lower levels of $F$. prausnitzii have been related to increased levels of inflammatory markers, obesity, diabetes, and immune-related diseases [89]. Since higher levels of TMAO are associated with heart failure and chronic kidney disease, recently, research has been focused on the discovery of inhibitors that block TMAO production as a therapeutic strategy to decrease the risk of cardiovascular or kidney disease [90]. It has been found that iodomethylcholine (IMC) and fluoromethylcholine (FMC), choline analogs which irreversibly inhibit microbial choline TMA lyase activity, led to reductions in plasma TMAO level and atherosclerotic lesion development in mice [91]. Regarding the possible role of TMAO in obesity, the full extent of the therapeutic potential of TMAO inhibition in obesity still needs to be investigated.

\section{Other microbiota-derived metabolites}

Glycoprotein acetyl

Glycoprotein acetyl, mainly $\alpha 1$-acid glycoprotein (GlycA), is a novel marker of low-grade inflammation that has been shown to increase in obese subjects [28] and obese pregnant women [22]. GlycA includes a complex heterogeneous nuclear magnetic resonance signal containing $\mathrm{N}$-acetyl sugar groups originating from multiple acute phase circulating glycoproteins [92]. It has been shown that GlycA is associated with obesity and insulin resistance [93, 94]. Moreover, GlycA was correlated with higher concentrations of triglycerides, LDL-C, and BCAA in obese individuals $[95,96]$. It was also demonstrated that specific gut bacterial groups were negatively associated with GlycA, which 
was further related to intake of fiber. Fiber intake was linked negatively with bacteria of the Firmicutes and Bacteroidetes phyla and linked positively with a genus of the Bacteroidetes phylum [97].

Hippuric acid

One of the urinary gut bacterial metabolites assessed in two included articles was hippuric acid. Ahmad et al. [28] and Calvani et al. [25] showed an inverse relationship of hippuric acid with obesity. Hippurate is a gut microbial-mammalian cometabolite of benzoic acid that can be made by gut Clostridium spp. from low-molecular-weight aromatic compounds and polyphenols, conjugated with glycine in the mitochondria, and then excreted in the urine [98]. Other human and animal models of obesity have consistently shown the association of urinary hippurate with leaner phenotypes and an altered gut bacterial composition [99-101]. Pallister et al. [102] showed that the plasma hippurate concentration was positively associated with the Ruminococcaceae and Rikenellaceae families and negatively associated with the Lachnospiraceae family. Hippurate was significantly associated with gut bacterial diversity, independently of dietary intake in a sample of 1,032 individuals, accounting for $6.5 \%$ of the variance in Shannon diversity index. Higher gut bacterial diversity and hippurate level were associated with a reduced risk of having metabolic syndrome [102].

Trigonelline

Trigonelline, an alkaloid formed by the methylation of niacin, is excreted in urine. Although trigonelline may have dietary sources, it is mainly biosynthesized by the gut microbiota during the methionine cycle. Decreased urinary level of trigonelline has been shown to be correlated with an alteration in energy and tryptophan metabolism. Calvani et al. [25] reported an inverse relationship between urinary trigonelline and obesity, suggesting that oxidative stress possibly has a role in the observed relationship. Trigonelline, a byproduct of the conversion of S-adenosylmethionine to S-adenosylhomocysteine consumed in the regenerating pathway of glutathione stores, is depleted by oxidative stress in obesity [103]. The variations in trigonelline excretion in obesity demonstrate the relationships between gut bacterial composition and function and the obese phenotype.

Xanthine

Xanthine is a purine base found in most human body tissues and fluids which is produced in the pathway of purine degradation and ultimately converted to uric acid by the xanthine oxidase enzyme [104]. It is a gut microbiota-derived metabolite that has been shown to decrease in obese individuals. Moreover, a decreased urinary level of xanthine was associated with an increased serum level of uric acid in obese subjects [25].

\section{CONCLUSION}

In this systematic review, we provided an overview of the role of gut microbiota-derived metabolites in obesity. These metabolites can affect multiple metabolic pathways in the host which lead to obesity. Some of these metabolites consistently decrease in obesity and its related metabolic complications, while others seem to increase as a result of host-microbiome interactions. Metabolomics studies have allowed identification of microbial markers associated with obesity across different populations and subsequently development of therapeutic strategies. Interventional studies with the aim of modulating gut microbiota and consequently the metabolic profile in obesity could also contribute to obesity management. There are various strategies for gut microbiota modulation, including the use of functional foods, probiotics, prebiotics, fecal microbiota transplantation, and bariatric surgery. However, a limited number of studies have assessed the alteration of gut microbiota, their metabolites, and the consequential functional effects after interventions in obesity. Currently, there is no consensus on which type of gut microbiotamodulating interventions will induce a better metabolic profile in obesity. Further studies are needed in this field to develop strategies for modifying the specific gut microbiota-derived metabolites. Moreover, considering the strain-dependent functions of some taxa, more studies are needed to investigate the relationship between gut microbiota and metabolites at the strain level.

\section{CONFLICT OF INTERESTS}

There is no conflict of interest to declare.

\section{AUTHOR CONTRIBUTIONS}

HE, concept, design, data collection, literature search, writing; PA, data collection, writing; AS, interpretation; SH, design, interpretation, writing; DS, design, interpretation, writing; BL, concept, design.

\section{REFERENCES}

1. Hruby A, Hu FB. 2015. The epidemiology of obesity: a big picture. Pharmacoeconomics 33: 673-689. [Medline] [CrossRef]

2. Ejtahed HS, Soroush AR, Angoorani P, Larijani B, Hasani-Ranjbar S. 2016. Gut microbiota as a target in the pathogenesis of metabolic disorders: a new approach to novel therapeutic agents. Horm Metab Res 48: 349-358. [Medline] [CrossRef]

3. Ejtahed HS, Angoorani P, Hasani-Ranjbar S, Siadat SD, Ghasemi N, Larijani B, Soroush AR. 2018. Adaptation of human gut microbiota to bariatric surgeries in morbidly obese patients: a systematic review. Microb Pathog 116: 13-21. [Medline] [CrossRef]

4. Ejtahed HS, Hasani-Ranjbar S, Larijani B. 2017. Human microbiome as an approach to personalized medicine. Altern Ther Health Med 23: 8-9. [Medline]

5. Ley RE, Turnbaugh PJ, Klein S, Gordon JI. 2006. Microbial ecology: human gut microbes associated with obesity. Nature 444: 1022-1023. [Medline] [CrossRef]

6. Duncan SH, Lobley GE, Holtrop G, Ince J, Johnstone AM, Louis P, Flint HJ. 2008. Human colonic microbiota associated with diet, obesity and weight loss. Int J Obes 32 : 1720-1724. [Medline] [CrossRef]

7. Schwiertz A, Taras D, Schäfer K, Beijer S, Bos NA, Donus C, Hardt PD. 2010. Microbiota and SCFA in lean and overweight healthy subjects. Obesity (Silver Spring) 18: 190-195. [Medline] [CrossRef]

8. Musso G, Gambino R, Cassader M. 2011. Interactions between gut microbiota and host metabolism predisposing to obesity and diabetes. Annu Rev Med 62: 361-380. [Medline] [CrossRef]

9. Liu R, Hong J, Xu X, Feng Q, Zhang D, Gu Y, Shi J, Zhao S, Liu W, Wang X, Xia H, Liu Z, Cui B, Liang P, Xi L, Jin J, Ying X, Wang X, Zhao X, Li W, Jia H, Lan Z, Li F, Wang R, Sun Y, Yang M, Shen Y, Jie Z, Li J, Chen X, Zhong H, Xie H, Zhang Y, Gu W, Deng X, Shen B, Xu X, Yang H, Xu G, Bi Y, Lai S, Wang J, Qi L, Madsen L, Wang J, Ning G, Kristiansen K, Wang W. 2017. Gut microbiome and serum metabolome alterations in obesity and after weight-loss intervention. Nat Med 23: 859-868. [Medline] [CrossRef]

10. Heianza Y, Sun D, Smith SR, Bray GA, Sacks FM, Qi L. 2018. Changes in gut microbiota-related metabolites and long-term successful weight loss in response to weight-loss diets: The POUNDS Lost Trial. Diabetes Care 41: 413-419. [Medline] [CrossRef]

11. Nicholson JK, Holmes E, Kinross J, Burcelin R, Gibson G, Jia W, Pettersson S. 2012. Host-gut microbiota metabolic interactions. Science 336: 1262-1267. [Medline] [CrossRef]

12. Palau-Rodriguez M, Tulipani S, Isabel Queipo-Ortuño M, Urpi-Sarda M, Tinahones FJ, Andres-Lacueva C. 2015. Metabolomic insights into the intricate gut microbial-host interaction in the development of obesity and type 2 diabetes. Front Microbiol 6: 1151. [Medline] [CrossRef]

13. Pedersen HK, Gudmundsdottir V, Nielsen HB, Hyotylainen T, Nielsen T, Jensen BA, Forslund K, Hildebrand F, Prifti E, Falony G, Le Chatelier E, Levenez F, Doré J, 
Mattila I, Plichta DR, Pöhö P, Hellgren LI, Arumugam M, Sunagawa S, Vieira-Silva S, Jørgensen T, Holm JB, Trošt K, Kristiansen K, Brix S, Raes J, Wang J, Hansen T, Bork P, Brunak S, Oresic M, Ehrlich SD, Pedersen O, MetaHIT Consortium 2016. Human gut microbes impact host serum metabolome and insulin sensitivity. Nature 535: 376-381. [Medline] [CrossRef]

14. Llorach R, Garcia-Aloy M, Tulipani S, Vazquez-Fresno R, Andres-Lacueva C. 2012. Nutrimetabolomic strategies to develop new biomarkers of intake and health effects. J Agric Food Chem 60: 8797-8808. [Medline] [CrossRef]

15. Quinones MP, Kaddurah-Daouk R. 2009. Metabolomics tools for identifying biomarkers for neuropsychiatric diseases. Neurobiol Dis 35: 165-176. [Medline] [CrossRef]

16. Faber JH, Malmodin D, Toft H, Maher AD, Crockford D, Holmes E, Nicholson JK, Dumas ME, Baunsgaard D. 2007. Metabonomics in diabetes research. J Diabetes Sci Technol 1: 549-557. [Medline] [CrossRef]

17. Postler TS, Ghosh S. 2017. Understanding the Holobiont: how microbial metabolites affect human health and shape the immune system. Cell Metab 26: 110-130. [Medline] [CrossRef]

18. Sharon G, Garg N, Debelius J, Knight R, Dorrestein PC, Mazmanian SK. 2014. Specialized metabolites from the microbiome in health and disease. Cell Metab 20: 719-730. [Medline] [CrossRef]

19. Bondia-Pons I, Maukonen J, Mattila I, Rissanen A, Saarela M, Kaprio J, Hakkarainen A, Lundbom J, Lundbom N, Hyötyläinen T, Pietiläinen KH, Orešič M. 2014. Metabolome and fecal microbiota in monozygotic twin pairs discordant for weight: a Big Mac challenge. FASEB J 28: 4169-4179. [Medline] [CrossRef]

20. Org E, Blum Y, Kasela S, Mehrabian M, Kuusisto J, Kangas AJ, Soininen P, Wang Z, Ala-Korpela M, Hazen SL, Laakso M, Lusis AJ. 2017. Relationships between gut microbiota, plasma metabolites, and metabolic syndrome traits in the METSIM cohort. Genome Biol 18: 70. [Medline] [CrossRef]

21. Tiihonen K, Ouwehand AC, Rautonen N. 2010. Effect of overweight on gastrointestinal microbiology and immunology: correlation with blood biomarkers. Br J Nutr 103: 1070-1078. [Medline] [CrossRef]

22. Houttu N, Mokkala K, Laitinen K. 2018. Overweight and obesity status in pregnant women are related to intestinal microbiota and serum metabolic and inflammatory profiles. Clin Nutr 376 Pt A: 1955-1966. [Medline] [CrossRef]

23. Payne AN, Chassard C, Zimmermann M, Müller P, Stinca S, Lacroix C. 2011. The metabolic activity of gut microbiota in obese children is increased compared with normal-weight children and exhibits more exhaustive substrate utilization. Nutr Diabetes 1: e12. [Medline] [CrossRef]

24. Piening BD, Zhou W, Contrepois K, Röst H, Gu Urban GJ, Mishra T, Hanson BM, Bautista EJ, Leopold S, Yeh CY, Spakowicz D, Banerjee I, Chen C, Kukurba K, Perelman D, Craig C, Colbert E, Salins D, Rego S, Lee S, Zhang C, Wheeler J, Sailani MR, Liang L, Abbott C, Gerstein M, Mardinoglu A, Smith U, Rubin DL, Pitteri S, Sodergren E, McLaughlin TL, Weinstock GM, Snyder MP. 2018. Integrative personal omics profiles during periods of weight gain and loss. Cell Syst 6: 157-170.e8. [Medline] [CrossRef]

25. Calvani R, Miccheli A, Capuani G, Tomassini Miccheli A, Puccetti C, Delfini M, Iaconelli A, Nanni G, Mingrone G. 2010. Gut microbiome-derived metabolites characterize a peculiar obese urinary metabotype. Int J Obes 34: 1095-1098. [Medline] [CrossRef]

26. Raman M, Ahmed I, Gillevet PM, Probert CS, Ratcliffe NM, Smith S, Greenwood R, Sikaroodi M, Lam V, Crotty P, Bailey J, Myers RP, Rioux KP. 2013. Fecal microbiome and volatile organic compound metabolome in obese humans with nonalcoholic fatty liver disease. Clin Gastroenterol Hepatol 11: 868-75.e1, 3. [Medline] [CrossRef]

27. López-Contreras BE, Morán-Ramos S, Villarruel-Vázquez R, Macías-Kauffer L, Villamil-Ramírez H, León-Mimila P, Vega-Badillo J, Sánchez-Muñoz F, LlanosMoreno LE, Canizalez-Román A, Del Río-Navarro B, Ibarra-González I, Vela-Amieva M, Villarreal-Molina T, Ochoa-Leyva A, Aguilar-Salinas CA, Canizales-Quinteros S 2018. Composition of gut microbiota in obese and normal-weight Mexican school-age children and its association with metabolic traits. Pediatr Obes 13: 381-388. [Medline] [CrossRef]

28. Ahmad MS, Alsaleh M, Kimhofer T, Ahmad S, Jamal W, Wali SO, Nicholson JK, Damanhouri ZA, Holmes E. 2017. Metabolic phenotype of obesity in a Saudi population. J Proteome Res 16: 635-644. [Medline] [CrossRef]

29. Druart C, Dewulf EM, Cani PD, Neyrinck AM, Thissen JP, Delzenne NM. 2014. Gut microbial metabolites of polyunsaturated fatty acids correlate with specific fecal bacteria and serum markers of metabolic syndrome in obese women. Lipids 49: 397-402. [Medline] [CrossRef]

30. McCormack SE, Shaham O, McCarthy MA, Deik AA, Wang TJ, Gerszten RE, Clish CB, Mootha VK, Grinspoon SK, Fleischman A. 2013. Circulating branched-chain amino acid concentrations are associated with obesity and future insulin resistance in children and adolescents. Pediatr Obes 8: 52-61. [Medline] [CrossRef]

31. Dejong CH, van de Poll MC, Soeters PB, Jalan R, Olde Damink SW. 2007. Aromatic amino acid metabolism during liver failure. J Nutr 137 Suppl 1: 1579S-1585S, discussion 1597S-1598S. [Medline] [CrossRef]

32. Cheng S, Rhee EP, Larson MG, Lewis GD, McCabe EL, Shen D, Palma MJ, Roberts LD, Dejam A, Souza AL, Deik AA, Magnusson M, Fox CS, O'Donnell CJ, Vasan RS, Melander O, Clish CB, Gerszten RE, Wang TJ. 2012. Metabolite profiling identifies pathways associated with metabolic risk in humans. Circulation 125: 2222-2231.
[Medline] [CrossRef]

33. Zeng Y, Lin Y, Li L, Li Y, Zhang X, Wang M, Chen Y, Luo L, Lu B, Xie Z, Liao Q. 2019. Targeted metabolomics for the quantitative measurement of 9 gut microbiota-host co-metabolites in rat serum, urine and feces by liquid chromatography-tandem mas spectrometry. J Chromatogr B Analyt Technol Biomed Life Sci 1110-1111: 133-143. [Medline] [CrossRef]

34. Konopelski P, Konop M, Gawrys-Kopczynska M, Podsadni P, Szczepanska A, Ufnal M. 2019. Indole-3-Propionic Acid, a tryptophan-derived bacterial metabolite, reduces weight gain in rats. Nutrients 11: E591. [Medline] [CrossRef]

35. Selmer T, Andrei PI. 2001. p-Hydroxyphenylacetate decarboxylase from Clostridium difficile. A novel glycyl radical enzyme catalysing the formation of p-cresol. Eur J Biochem 268: 1363-1372. [Medline] [CrossRef]

36. Carrasco-Pozo C, Gotteland M, Castillo RL, Chen C. 2015. 3,4-Dihydroxyphenylacetic acid, a microbiota-derived metabolite of quercetin, protects against pancreatic $\beta$-cells dysfunction induced by high cholesterol. Exp Cell Res 334: 270-282. [Medline] [CrossRef]

37. Rorstad O. 2005. Prognostic indicators for carcinoid neuroendocrine tumors of the gastrointestinal tract. J Surg Oncol 89: 151-160. [Medline] [CrossRef]

38. Russell WR, Duncan SH, Scobbie L, Duncan G, Cantlay L, Calder AG, Anderson SE, Flint HJ. 2013. Major phenylpropanoid-derived metabolites in the human gut can arise from microbial fermentation of protein. Mol Nutr Food Res 57: 523-535. [Medline] [CrossRef]

39. Wang TJ, Larson MG, Vasan RS, Cheng S, Rhee EP, McCabe E, Lewis GD, Fox CS, Jacques PF, Fernandez C, O’Donnell CJ, Carr SA, Mootha VK, Florez JC, Souza A, Melander O, Clish CB, Gerszten RE. 2011. Metabolite profiles and the risk of developing diabetes. Nat Med 17: 448-453. [Medline] [CrossRef]

40. Magnusson M, Lewis GD, Ericson U, Orho-Melander M, Hedblad B, Engström G Ostling G, Clish C, Wang TJ, Gerszten RE, Melander O. 2013. A diabetes-predictive amino acid score and future cardiovascular disease. Eur Heart J 34: 1982-1989. [Medline] [CrossRef]

41. Newgard CB, An J, Bain JR, Muehlbauer MJ, Stevens RD, Lien LF, Haqq AM, Shah SH, Arlotto M, Slentz CA, Rochon J, Gallup D, Ilkayeva O, Wenner BR, Yancy WS Jr, Eisenson H, Musante G, Surwit RS, Millington DS, Butler MD, Svetkey LP. 2009. A branched-chain amino acid-related metabolic signature that differentiates obese and lean humans and contributes to insulin resistance. Cell Metab 9: 311-326. [Medline] [CrossRef]

42. Um SH, D'Alessio D, Thomas G. 2006. Nutrient overload, insulin resistance, and ribosomal protein S6 kinase 1, S6K1. Cell Metab 3: 393-402. [Medline] [CrossRef]

43. Koren O, Goodrich JK, Cullender TC, Spor A, Laitinen K, Bäckhed HK, Gonzalez A, Werner JJ, Angenent LT, Knight R, Bäckhed F, Isolauri E, Salminen S, Ley RE. 2012. Host remodeling of the gut microbiome and metabolic changes during pregnancy. Cell 150: 470-480. [Medline] [CrossRef]

44. Ottosson F, Brunkwall L, Ericson U, Nilsson PM, Almgren P, Fernandez C, Melander O, Orho-Melander M. 2018. Connection between BMI-related plasma metabolite profile and gut microbiota. J Clin Endocrinol Metab 103: 1491-1501. [Medline] [CrossRef]

45. Menni C, Jackson MA, Pallister T, Steves CJ, Spector TD, Valdes AM. 2017. Gut microbiome diversity and high-fibre intake are related to lower long-term weight gain. Int J Obes 41: 1099-1105. [Medline] [CrossRef]

46. Lippert K, Kedenko L, Antonielli L, Kedenko I, Gemeier C, Leitner M, Kautzky-Willer A, Paulweber B, Hackl E. 2017. Gut microbiota dysbiosis associated with glucose metabolism disorders and the metabolic syndrome in older adults. Benef Microbes 8 : 545-556. [Medline] [CrossRef]

47. Hooper LV, Wong MH, Thelin A, Hansson L, Falk PG, Gordon JI. 2001. Molecular analysis of commensal host-microbial relationships in the intestine. Science 291: 881-884. [Medline] [CrossRef]

48. Hermanussen M, García AP, Sunder M, Voigt M, Salazar V, Tresguerres JA. 2006 Obesity, voracity, and short stature: the impact of glutamate on the regulation of appetite. Eur J Clin Nutr 60: 25-31. [Medline] [CrossRef]

49. He K, Du S, Xun P, Sharma S, Wang H, Zhai F, Popkin B. 2011. Consumption of monosodium glutamate in relation to incidence of overweight in Chinese adults: China Health and Nutrition Survey (CHNS). Am J Clin Nutr 93: 1328-1336. [Medline] [CrossRef]

50. de Souza AZZ, Zambom AZ, Abboud KY, Reis SK, Tannihão F, Guadagnini D, Saad MJ, Prada PO. 2015. Oral supplementation with L-glutamine alters gut microbiota of obese and overweight adults: a pilot study. Nutrition 31: 884-889. [Medline] [CrossRef]

51. Roth E. 2008. Nonnutritive effects of glutamine. J Nutr 138: 2025S-2031S. [Medline] [CrossRef]

52. Greenfield JR, Farooqi IS, Keogh JM, Henning E, Habib AM, Blackwood A, Reimann F, Holst JJ, Gribble FM. 2009. Oral glutamine increases circulating glucagon-like peptide 1, glucagon, and insulin concentrations in lean, obese, and type 2 diabetic subjects. Am J Clin Nutr 89: 106-113. [Medline] [CrossRef]

53. Qin J, Li Y, Cai Z, Li S, Zhu J, Zhang F, Liang S, Zhang W, Guan Y, Shen D, Peng Y, Zhang D, Jie Z, Wu W, Qin Y, Xue W, Li J, Han L, Lu D, Wu P, Dai Y, Sun X, Li Z, Tang A, Zhong S, Li X, Chen W, Xu R, Wang M, Feng Q, Gong M, Yu J, Zhang Y, Zhang M, Hansen T, Sanchez G, Raes J, Falony G, Okuda S, Almeida M, LeChatelier E, Renault P, Pons N, Batto JM, Zhang Z, Chen H, Yang R, Zheng W, Li S, Yang H, Wang J, Ehrlich SD, Nielsen R, Pedersen O, Kristiansen K, Wang J. 2012. A metagenome-wide 
association study of gut microbiota in type 2 diabetes. Nature 490: 55-60. [Medline] [CrossRef]

54. Fu J, Bonder MJ, Cenit MC, Tigchelaar EF, Maatman A, Dekens JA, Brandsma E, Marczynska J, Imhann F, Weersma RK, Franke L, Poon TW, Xavier RJ, Gevers D, Hofker MH, Wijmenga C, Zhernakova A. 2015. The gut microbiome contributes to a substantial proportion of the variation in blood lipids. Circ Res 117: 817-824. [Medline] [CrossRef]

55. Goodrich JK, Waters JL, Poole AC, Sutter JL, Koren O, Blekhman R, Beaumont M, Van Treuren W, Knight R, Bell JT, Spector TD, Clark AG, Ley RE. 2014. Human genetics shape the gut microbiome. Cell 159: 789-799. [Medline] [CrossRef]

56. Méndez-Salazar EO, Ortiz-López MG, Granados-Silvestre MLA, Palacios-González B, Menjivar M. 2018. Altered gut microbiota and compositional changes in Firmicutes and Proteobacteria in Mexican undernourished and obese children. Front Microbiol 9: 2494. [Medline] [CrossRef]

57. Khan MT, Nieuwdorp M, Bäckhed F. 2014. Microbial modulation of insulin sensitivity. Cell Metab 20: 753-760. [Medline] [CrossRef]

58. Flanagan JL, Simmons PA, Vehige J, Willcox MD, Garrett Q. 2010. Role of carnitine in disease. Nutr Metab (Lond) 7: 30. [Medline] [CrossRef]

59. Niwa T. 2010. Indoxyl sulfate is a nephro-vascular toxin. J Ren Nutr 20 Suppl: S2-S6. [Medline] [CrossRef]

60. Phetcharaburanin J, Lees H, Marchesi JR, Nicholson JK, Holmes E, Seyfried F, Li JV. 2016. Systemic characterization of an obese phenotype in the Zucker rat model defining metabolic axes of energy metabolism and host-microbial interactions. J Proteome Res 15: 1897-1906. [Medline] [CrossRef]

61. Yu HT, Fu XY, Xu B, Zuo LL, Ma HB, Wang SR. 2018. Untargeted metabolomics approach (UPLC-Q-TOF-MS) explores the biomarkers of serum and urine in overweight/obese young men. Asia Pac J Clin Nutr 27: 1067-1076. [Medline]

62. Wikoff WR, Anfora AT, Liu J, Schultz PG, Lesley SA, Peters EC, Siuzdak G. 2009. Metabolomics analysis reveals large effects of gut microflora on mammalian blood metabolites. Proc Natl Acad Sci USA 106: 3698-3703. [Medline] [CrossRef]

63. Bäckhed F, Crawford PA. 1801. 2010. Coordinated regulation of the metabolome and lipidome at the host-microbial interface. Biochimica et Biophysica Acta (BBA)-. Molecular and Cell Biology of Lipids 240-245.

64. Alcock J, Lin HC. 2015. Fatty acids from diet and microbiota regulate energy metabolism. F1000 Research. 4 (F1000 Faculty Rev).

65. Summers LK, Fielding BA, Bradshaw HA, Ilic V, Beysen C, Clark ML, Moore NR, Frayn KN. 2002. Substituting dietary saturated fat with polyunsaturated fat changes abdominal fat distribution and improves insulin sensitivity. Diabetologia 45: 369-377. [Medline] [CrossRef]

66. Flint HJ, Bayer EA, Rincon MT, Lamed R, White BA. 2008. Polysaccharide utilization by gut bacteria: potential for new insights from genomic analysis. Nat Rev Microbiol 6 : 121-131. [Medline] [CrossRef]

67. Olli K, Salli K, Alhoniemi E, Saarinen M, Ibarra A, Vasankari T, Rautonen N, Tiihonen K. 2015. Postprandial effects of polydextrose on satiety hormone responses and subjective feelings of appetite in obese participants. Nutr J 14: 2. [Medline] [CrossRef]

68. Samuel BS, Shaito A, Motoike T, Rey FE, Backhed F, Manchester JK, Hammer RE, Williams SC, Crowley J, Yanagisawa M, Gordon JI. 2008. Effects of the gut microbiota on host adiposity are modulated by the short-chain fatty-acid binding $\mathrm{G}$ protein-coupled receptor, Gpr41. Proc Natl Acad Sci USA 105: 16767-16772. [Medline] [CrossRef]

69. Kimura I, Inoue D, Hirano K, Tsujimoto G. 2014. The SCFA receptor GPR43 and energy metabolism. Front Endocrinol (Lausanne) 5: 85. [Medline] [CrossRef]

70. Chakraborti CK. 2015. New-found link between microbiota and obesity. World J Gastrointest Pathophysiol 6: 110-119. [Medline] [CrossRef]

71. Gauffin Cano P, Santacruz A, Moya Á, Sanz Y. 2012. Bacteroides uniformis CECT 7771 ameliorates metabolic and immunological dysfunction in mice with high-fat-diet induced obesity. PLoS One 7: e41079. [Medline] [CrossRef]

72. Rosenbaum M, Knight R, Leibel RL. 2015. The gut microbiota in human energy homeostasis and obesity. Trends Endocrinol Metab 26: 493-501. [Medline] [CrossRef]

73. Kasai C, Sugimoto K, Moritani I, Tanaka J, Oya Y, Inoue H, Tameda M, Shiraki K, Ito M, Takei Y, Takase K. 2015. Comparison of the gut microbiota composition between obese and non-obese individuals in a Japanese population, as analyzed by terminal restriction fragment length polymorphism and next-generation sequencing. BMC Gastroenterol 15: 100. [Medline] [CrossRef]

74. Bonder MJ, Kurilshikov A, Tigchelaar EF, Mujagic Z, Imhann F, Vila AV, Deelen P, Vatanen T, Schirmer M, Smeekens SP, Zhernakova DV, Jankipersadsing SA, Jaeger M, Oosting M, Cenit MC, Masclee AA, Swertz MA, Li Y, Kumar V, Joosten L, Harmsen H, Weersma RK, Franke L, Hofker MH, Xavier RJ, Jonkers D, Netea MG, Wijmenga C, Fu J, Zhernakova A. 2016. The effect of host genetics on the gut microbiome. Nat Genet 48: 1407-1412. [Medline] [CrossRef]

75. Zhang H, DiBaise JK, Zuccolo A, Kudrna D, Braidotti M, Yu Y, Parameswaran P, Crowell MD, Wing R, Rittmann BE, Krajmalnik-Brown R. 2009. Human gut microbiota in obesity and after gastric bypass. Proc Natl Acad Sci USA 106: 2365-2370. [Medline] [CrossRef]

76. Wegner GH, Foster EM. 1963. Incorporation of isobutyrate and valerate into cellular plasmalogen by Bacteroides succinogenes. J Bacteriol 85: 53-61. [Medline] [CrossRef]

77. Nyangale EP, Mottram DS, Gibson GR. 2012. Gut microbial activity, implications for health and disease: the potential role of metabolite analysis. J Proteome Res 11:
5573-5585. [Medline] [CrossRef]

78. Park Y, Albright KJ, Liu W, Storkson JM, Cook ME, Pariza MW. 1997. Effect of conjugated linoleic acid on body composition in mice. Lipids 32: 853-858. [Medline] [CrossRef]

79. Koba K, Akahoshi A, Yamasaki M, Tanaka K, Yamada K, Iwata T, Kamegai T, Tsutsumi K, Sugano M. 2002. Dietary conjugated linolenic acid in relation to CLA differently modifies body fat mass and serum and liver lipid levels in rats. Lipids 37: 343-350. [Medline] [CrossRef]

80. Park HG, Cho HT, Song MC, Kim SB, Kwon EG, Choi NJ, Kim YJ. 2012. Production of a conjugated fatty acid by Bifidobacterium breve LMC520 from $\alpha$-linolenic acid: conjugated linolenic acid (CLnA). J Agric Food Chem 60: 3204-3210. [Medline] [CrossRef]

81. Devillard E, McIntosh FM, Duncan SH, Wallace RJ. 2007. Metabolism of linoleic acid by human gut bacteria: different routes for biosynthesis of conjugated linoleic acid. $\mathrm{J}$ Bacteriol 189: 2566-2570. [Medline] [CrossRef]

82. Begley M, Hill C, Gahan CG. 2006. Bile salt hydrolase activity in probiotics. Appl Environ Microbiol 72: 1729-1738. [Medline] [CrossRef]

83. Keitel V, Kubitz R, Häussinger D. 2008. Endocrine and paracrine role of bile acids. World J Gastroenterol 14: 5620-5629. [Medline] [CrossRef]

84. Del Chierico F, Abbatini F, Russo A, Quagliariello A, Reddel S, Capoccia D, Caccamo R, Ginanni Corradini S, Nobili V, De Peppo F, Dallapiccola B, Leonetti F, Silecchia G, Putignani L. 2018. Gut microbiota markers in obese adolescent and adult patients: age-dependent differential patterns. Front Microbiol 9: 1210. [Medline] [CrossRef]

85. Vrieze A, Out C, Fuentes S, Jonker L, Reuling I, Kootte RS, van Nood E, Holleman F, Knaapen M, Romijn JA, Soeters MR, Blaak EE, Dallinga-Thie GM, Reijnders D, Ackermans MT, Serlie MJ, Knop FK, Holst JJ, van der Ley C, Kema IP, Zoetendal EG, de Vos WM, Hoekstra JB, Stroes ES, Groen AK, Nieuwdorp M. 2014. Impact of oral vancomycin on gut microbiota, bile acid metabolism, and insulin sensitivity. J Hepatol 60: 824-831. [Medline] [CrossRef]

86. Fiorucci S, Distrutti E. 2015. Bile acid-activated receptors, intestinal microbiota, and the treatment of metabolic disorders. Trends Mol Med 21: 702-714. [Medline] [CrossRef]

87. Alemán JO, Bokulich NA, Swann JR, Walker JM, De Rosa JC, Battaglia T, Costabile A, Pechlivanis A, Liang Y, Breslow JL, Blaser MJ, Holt PR. 2018. Fecal microbiota and bile acid interactions with systemic and adipose tissue metabolism in diet-induced weight loss of obese postmenopausal women. J Transl Med 16: 244. [Medline] [CrossRef]

88. Sayin SI, Wahlström A, Felin J, Jäntti S, Marschall HU, Bamberg K, Angelin B, Hyötyläinen T, Orešič M, Bäckhed F. 2013. Gut microbiota regulates bile acid metabolism by reducing the levels of tauro-beta-muricholic acid, a naturally occurring FXR antagonist. Cell Metab 17: 225-235. [Medline] [CrossRef]

89. Graessler J, Qin Y, Zhong H, Zhang J, Licinio J, Wong ML, Xu A, Chavakis T, Bornstein AB, Ehrhart-Bornstein M, Lamounier-Zepter V, Lohmann T, Wolf T, Bornstein SR. 2013. Metagenomic sequencing of the human gut microbiome before and after bariatric surgery in obese patients with type 2 diabetes: correlation with inflammatory and metabolic parameters. Pharmacogenomics J 13: 514-522. [Medline] [CrossRef]

90. Le Bras A. 2018. Targeting the gut to protect the heart. Nat Rev Cardiol 15: 581. [Medline] [CrossRef]

91. Wang Z, Roberts AB, Buffa JA, Levison BS, Zhu W, Org E, Gu X, Huang Y, ZamanianDaryoush M, Culley MK, DiDonato AJ, Fu X, Hazen JE, Krajcik D, DiDonato JA, Lusis AJ, Hazen SL. 2015. Non-lethal inhibition of gut microbial trimethylamine production for the treatment of atherosclerosis. Cell 163: 1585-1595. [Medline] [CrossRef]

92. Otvos JD, Shalaurova I, Wolak-Dinsmore J, Connelly MA, Mackey RH, Stein JH, Tracy RP. 2015. GlycA: a composite nuclear magnetic resonance biomarker of systemic inflammation. Clin Chem 61: 714-723. [Medline] [CrossRef]

93. Lozupone CA, Knight R. 2008. Species divergence and the measurement of microbial diversity. FEMS Microbiol Rev 32: 557-578. [Medline] [CrossRef]

94. Bao W, Dar S, Zhu Y, Wu J, Rawal S, Li S, Weir NL, Tsai MY, Zhang C. 2018. Plasma concentrations of lipids during pregnancy and the risk of gestational diabetes mellitus: a longitudinal study. J Diabetes 10: 487-495. [Medline] [CrossRef]

95. Bogl LH, Kaye SM, Rämö JT, Kangas AJ, Soininen P, Hakkarainen A, Lundbom J, Lundbom N, Ortega-Alonso A, Rissanen A, Ala-Korpela M, Kaprio J, Pietiläinen KH. 2016. Abdominal obesity and circulating metabolites: a twin study approach. Metabolism 65: 111-121. [Medline] [CrossRef]

96. Mokkala K, Pellonperä O, Röytiö H, Pussinen P, Rönnemaa T, Laitinen K. 2017. Increased intestinal permeability, measured by serum zonulin, is associated with metabolic risk markers in overweight pregnant women. Metabolism 69: 43-50. [Medline] [CrossRef]

97. Röytiö H, Mokkala K, Vahlberg T, Laitinen K. 2017. Dietary intake of fat and fibre according to reference values relates to higher gut microbiota richness in overweight pregnant women. Br J Nutr 118: 343-352. [Medline] [CrossRef]

98. Nicholson JK, Holmes E, Wilson ID. 2005. Gut microorganisms, mammalian metabolism and personalized health care. Nat Rev Microbiol 3: 431-438. [Medline] [CrossRef]

99. Elliott P, Posma JM, Chan Q, Garcia-Perez I, Wijeyesekera A, Bictash M, Ebbels TM, Ueshima H, Zhao L, van Horn L, Daviglus M, Stamler J, Holmes E, Nicholson JK. 2015. Urinary metabolic signatures of human adiposity. Sci Transl Med 7: $285 \mathrm{ra} 62$. [Medline] [CrossRef] 
100. Waldram A, Holmes E, Wang Y, Rantalainen M, Wilson ID, Tuohy KM, McCartney AL, Gibson GR, Nicholson JK. 2009. Top-down systems biology modeling of host metabotype-microbiome associations in obese rodents. J Proteome Res 8: 2361-2375. [Medline] [CrossRef]

101. Handl S, German AJ, Holden SL, Dowd SE, Steiner JM, Heilmann RM, Grant RW, Swanson KS, Suchodolski JS. 2013. Faecal microbiota in lean and obese dogs. FEMS Microbiol Ecol 84: 332-343. [Medline] [CrossRef]

102. Pallister T, Jackson MA, Martin TC, Zierer J, Jennings A, Mohney RP, MacGregor A, Steves CJ, Cassidy A, Spector TD, Menni C. 2017. Hippurate as a metabolomic marker of gut microbiome diversity: modulation by diet and relationship to metabolic syndrome. Sci Rep 7: 13670. [Medline] [CrossRef]

103. Sun J, Schnackenberg LK, Holland RD, Schmitt TC, Cantor GH, Dragan YP, Beger RD. 2008. Metabonomics evaluation of urine from rats given acute and chronic doses of acetaminophen using NMR and UPLC/MS. J Chromatogr B Analyt Technol Biomed Life Sci 871: 328-340. [Medline] [CrossRef]

104. Voet D, Voet J, Pratt C. 2008. The major pathways of purine catabolism in animals. Fundamentals of biochemistry: life at the molecular level. 840 . 